\title{
Anterograde Tracing of Trigeminal Afferent Pathways from the Murine Tooth Pulp to Cortex Using Herpes Simplex Virus Type 1
}

\author{
Edward M. Barnett,, Gregory D. Evans, ${ }^{2}$ Ning Sun, ${ }^{3}$ Stanley Perlman, ${ }^{1,3}$ and Martin D. Cassell ${ }^{1,4}$ \\ ${ }^{1}$ Neuroscience Program, ${ }^{2}$ College of Dentistry, ${ }^{3}$ Departments of Microbiology and Pediatrics, and ${ }^{4}$ Department of \\ Anatomy, University of lowa, lowa City, lowa 52242
}

Due to its predominantly nociceptive innervation, viral tracing from the tooth pulp provides a potential means for tracing central pain pathways. The neural pathways from the tooth pulp to cortex were determined using in situ hybridization to detect the anterograde transneuronal spread of herpes simplex virus type 1 strain $\mathrm{H} 129$ following inoculation into the murine mandibular incisor pulp. Virus first appeared in the brain at day 3 in the dorsomedial region of all three subnuclei of the spinal trigeminal nucleus and the principal sensory nucleus. By days 5-6 virus had spread to the contralateral medial nucleus of the medial geniculate complex, posterior thalamus, and ventroposteromedial thalamus. At days 7-8 virus was detected in laminae IV and Va of the primary somatosensory cortex and lamina IV of the secondary somatosensory cortex in regions previously shown to receive input from the lower jaw. Several mice also showed infection of laminae II/III of the ipsilateral dysgranular insular cortex, along with labeling for virus in the ipsilateral external lateral parabrachial nucleus, posterior thalamus, and posterior basolateral amygdala.

Our results are highly consistent with previous tracing and electrophysiological studies utilizing the tooth pulp and with studies implicating the infected structures in nociception. Viral spread appeared to define two separate afferent systems with infection of structures which have been implicated in the sensory-discriminative aspects of pain, such as the ventroposteromedial thalamus and somatosensory cortex, as well as in the dysgranular Insular cortex and related subcortical nuclei which may have a role in the affective-motivational aspects of pain.

[Key words: herpes simplex virus type 1, anterograde viral tracing, trigeminal, nociception, tooth pulp, insular cortex]

Trigeminal sensory pathways convey nociceptive information originating from a wide range of cranial structures, including the cutaneous and mucosal surfaces, cornea, and meninges, as well as the cranial bones and teeth. The most well-studied of these

\footnotetext{
Received June 13, 1994; revised Oct. 18, 1994; accepted Nov. 1, 1994

This work was supported by grants from the National Institutes of Health (NS24401 and DC01311) and the National Multiple Sclerosis Society (RG2117A1). S.P. was supported by a Research Career Development Award from the NIH, E.M.B. by a Predoctoral M.D.-Ph.D. Fellowship (MH10384) from the NIMH, and N.S. by NIH Training Grant T32 AI07343. We thank Drs. Gerald Gebhardt and Richard Traub for helpful discussions, and Paul Reimann for photographic assistance.

Correspondence should be addressed to Di. M. D. Cassell, Departument of Anatomy, University of Iowa, Iowa City, IA 52242.

Copyright (C) 1995 Society for Neuroscience $0270-6474 / 95 / 152972-13 \$ 05.00 / 0$
}

pathways is that arising from the dental pulp, not only because of its clinical significance but also because other than a small complement of postganglionic sympathetic fibers and mechanoreceptors, the fibers in pulpal afferents are thought to be entirely nociceptive (Sessle, 1987). In the rat, intrapulpal application of WGA-HRP transganglionically labels afferent terminals throughout the ipsilateral trigeminal sensory complex, including the principal sensory nucleus, and the partes oralis, interpolaris, and caudalis (Marfurt and Turner, 1984). Physiological studies suggest that the pars caudalis is most strongly associated with the transmission of dental nociceptive information, though the other components of the trigeminal sensory complex appear to be involved as well.

Much of our current understanding of further CNS structures involved in relaying and processing dental nociceptive information comes from electrophysiological studies (e.g., Albe-Fessard et al., 1985), though anatomical studies of trigeminothalamic, trigeminomesencephalic, and trigeminopontoamygdaloid pathways have contributed significantly (Peschanski; 1984; Bernard et al., 1991; Yoshida et al., 1991). A large number of mesencephalic (e.g., parabrachial complex, central gray), thalanic (e.g., ventroposteromedial, centromedian, posterior, submedial, parafascicular nuclei), hypothalamic (e.g., lateral hypothalamus, arcuate nucleus), and forebrain (e.g., central amygdaloid nucleus) areas have been demonstrated physiologically to contain neurons responsive to activation of trigeminal nociceptive pathways, though the anatomical bases for these responses are still unclear. Even less clearly understood are the cortical areas involved in high level processing of trigeminal nociceptive information (Roland, 1992; Snow et al., 1992). Recent anatomical and physiological studies (Yoshida et al., 1991; Snow et al., 1992) suggest that there are two distinctly different representations of nociception in the cortex: one, associated with the somatosensory cortex, is involved primarily in the topographical localization of painful or noxious stimuli; the other, associated with the ventral orbital cortex, is concerned with "affectivemotivational" aspects of pain. How nociceptive information is relayed to these separate areas remains largely unknown.

The present study has utilized the spread of strain H129 of herpes simplex virus 1 (HSV-1) following inoculation into the mouse mandibular incisor tooth pulp to determine the nature and extent of structures which are transneuronally connected to the tooth pulp and therefore possible recipients of nociceptive information. Strain H129 spreads transneuronally in an anterograde direction, and has been used to trace sequential neural pathways in the basal ganglia (Zemanick et al., 1991).

A preliminary report of this work has appeared in abstract form (Barnett et al., 1993b). 


\section{Materials and Methods}

\section{Animals}

Forty-six young adult male (5 weeks old) $\mathrm{Balb} / \mathrm{c}$ mice purchased from Sasco Laboratories (Omaha, NE) were used in these studies. For surgeries, mice were anesthetized by intraperitoneal injections $(52.5 \mathrm{mg} /$ $\mathrm{kg}$ ) of a sodium pentobarbital solution (Shipley and Geinisman, 1984). All surgical procedures were approved by the Institutional Animal Care and Use Committee at the University of Iowa.

\section{Virus}

Strain H129 of HSV-1 (kindly provided by Dr. William Stroop, Baylor College of Medicine) was grown on RK13 cells and titered on Vero cells. The virus was maintained frozen at $-70^{\circ} \mathrm{C}$ in tissue culture media.

\section{Inoculations}

Tooth pulp inoculations. Each mouse was deeply anesthetized and the free gingiva was removed from the left mandibular incisor. The erupted part of the incisor was then removed just coronal to the gingival attachment using a cutting burr on a high-speed dental handpiece. Any gingival bleeding encountered during the procedure was either cauterized or blotted to secure hemostasis. Removal of the incisor at the level of the gingival attachment provided adequate access to the pulp canal in mice up to 6 weeks of age. The pulp canal was penetrated and enlarged using endodontic files and $6 \mu \mathrm{l}$ (containing $6 \times 10^{4}$ plaquefonning units) of HSV-1 strain $\mathrm{H} 129$ was delivered into the cavitation with a microsyringe. The tooth was subsequently sealed with a temporary dental cement. Postsurgically, mastication was not significantly altered, and supereruption (which is normally continuous in the rodent) of the surgically treated incisor occurred following the procedure. Four mice each were killed at $3,4,5,6$, and $8 \mathrm{~d}$ postinoculation (p.i.) and seven mice at $7 \mathrm{~d}$ p.i. by exsanguination via cardiac perfusion with $\mathrm{PBS}$ under deep pentobarbital anesthesia. Mice generally did not survive the infection later than $8 \mathrm{~d}$ p.i. The brains were then prepared for in situ hybridization as previously described (Barnett et al., 1993a). The ipsilateral and contralateral semilunar ganglia were also harvested from mice killed at $3 \mathrm{~d}$.

Control inoculations. Inoculation into the tooth pulp has the advantage that virus is delivered into a small cavity with a specific trigeminal innervation which is then sealed. As such, olher intraoral structures are unlikely to be exposed to virus. A study in which WGA-HRP was injected into the mandibular incisor tooth pulp found that with careful technique the inoculation could be restricted to the pulp chamber without leakage into gingival or periapical tissues (Takemura et al., 1991). The most likely location for potential viral leakage from the tooth pulp is the apical foramen of the tooth where the pulpal innervation enters. This might result in exposure of the innervation of the surrounding gingiva and the periodontal ligament to virus. Infection of the innervation of the periodontal ligament was assessed by examination of the mesencephalic nucleus of $\mathrm{V}$ for evidence of viral infection following tooth pulp inoculation. As a control for viral uptake by trigeminal neurons innervating the gingival and oral mucosa, 5 mice received $6 \mu l$ inoculations directly into the oral cavity. Mice were killed between 4 $8 \mathrm{~d}$ p.i., and brains were prepared for in situ hybridization.

The tooth pulp also receives an efferent sympathetic innervation via the superior cervical ganglion. Although HSV-1 strain $\mathrm{H} 129$ has been shown to spread solely in an anterograde direction, potential viral spread along this efferent pathway was evaluated by performing in situ hybridization on sections the thoracic spinal cords of mice at day 4 p.i. Furthermore, four mice were sympathectomized by bilateral extirpation of the superior cervical ganglion $24-48 \mathrm{hr}$ prior to tooth pulp inoculation of virus. Mice were killed between 5-8 d p.i. and brains prepared for in situ hybridization.

Hematogenous spread of HSV-1 to the brain has been shown to result in a diffuse infection with the initial sites of infection noted adjacent to small cerebral vessels (Johnson, 1964). To control for the possibility of hematogenous spread, five mice received intravenous inoculations of $10^{4}$ plaque forming units of HSV-1 strain $\mathrm{H} 129$ in $500 \mu \mathrm{l}$ of PBS into the tail vein under methoxyflurane anesthesia. Two mice were killed at 7 and at $8 \mathrm{~d}$ p.i., one mouse at $6 \mathrm{~d} \mathrm{p.i.,} \mathrm{and} \mathrm{brains} \mathrm{were} \mathrm{prepared} \mathrm{for}$ in situ hybridization.

In situ hybridization. This technique was used to detect viral nucleic acid since it is more sensitive than immunohistochemistry and the procedure enables easy processing of a large number of sections for each brain. An anti-sense ${ }^{35} \mathrm{~S}$-labeled RNA probe for HSV-1 was synthesized from a plasmid encoding the VP5 gene of HSV-1 (kindly provided by Dr. E. Wagner, University of California at Irvine) and in situ hybridization performed as previously described (Perlman et al., 1988; Barnett et al., 1993a). Briefly, $35 \mu \mathrm{m}$ coronal brain sections were cut at $100-$ $200 \mu \mathrm{m}$ intervals on a cryostat, collected on silane-treated slides, fixed, treated with proteinase $\mathrm{K}$, and acetylated. Approximately $10^{6} \mathrm{cpm}$ of probe in hybridization solution was applicd to each slidc. After annealing overnight, slides were treated with RNase and washes of increasing stringency. Slides were then placed on film for several days at $4^{\circ} \mathrm{C}$, followed by dipping in NTB-2 photographic emulsion (Kodak, Rochester, NY) for a 2 week exposure. After development and staining with cresyl violet, slides were examined by bright-field and dark-field light microscopy to localize viral nucleic acid in the brain. Infection of a cell was evidenced by labeling (i.e., silver grains) overlying the cell body, as this is the location of viral nucleic acid production.

\section{Results}

\section{Control inoculations}

Infection of the mesencephalic nucleus of the trigeminal nerve, which would be expected to occur with viral leakage from the apical foramen and infection of the innervation to the periodontal ligament (e.g., Gonzalo-Sanz and Insausti, 1980), was not seen (data not shown). Of the five mice which received inoculations of HSV-1 strain H129 directly into the oral cavity, viral nucleic acid was detected by in situ hybridization in only one case. This mouse showed a pattern of infection consistent with infection via both the maxillary and mandibular divisions of the trigeminal nerve and the vagus nerve with heavy labeling in the dorsal vagal complex and spinal trigeminal nucleus bilaterally (data not shown). Mice receiving intravenous inoculations of HSV-1 strain H129 were killed at 6,7 , and $8 \mathrm{~d}$ p.i. None of the five mice examined showed any labeling for viral nucleic acid anywhere in the brain (data not shown). Thus, the data clearly indicate that transneuronal spread from the oral mucosa, including the intact gingiva, and hematogenous spread from the tooth pulp are not compromising factors in the present data. The pattern of viral labeling in the brain was also not consistent with previously published reports of HSV-1 spread via the cerebrospinal fluid following inoculation into the lateral ventricle (McLean et al., 1989; Barnett et al., 1993a).

No labeling of viral nucleic acid was detected in the thoracic spinal cord, indicating that retrograde movement of virus along pulpal sympathetic efferents into the intermediolateral cell column and consequent transneuronal spread did not occur. Consistent with this, the pattern of viral labeling in sympathectomized animals was not different from that seen in intact animals following tooth pulp inoculations.

\section{Tooth pulp inoculations}

HSV-1 was detected in the brains of all mice receiving tooth pulp inoculations. Although there is some variability in the particular structures infected at any given time point (Table 1), as also seen in previous studies examining HSV-1 spread (McLean et al., 1989; Barnett et al., 1993a), the data are presented according to the time p.i. at which the animals were sacrificed This variability is likely due to differences across mice in the extent of the infection at a given time p.i., and not differences in the overall pathways of viral spread (i.e., any differences between the day 5 p.i. mice in the structures infected reflects the fact that virus had spread more quickly along the same pathways in some mice as compared to others).

Day 3. Ipsilateral semilunar ganglia from mice at day 3 showed labeling over ganglion cell bodies in the posterolateral protuberance extending into the mandibular division at the bifurcation of the mandibular and ophthalmomaxillary divisions 
Table 1. Brain structures infected following tooth pulp inoculation of HSV-1

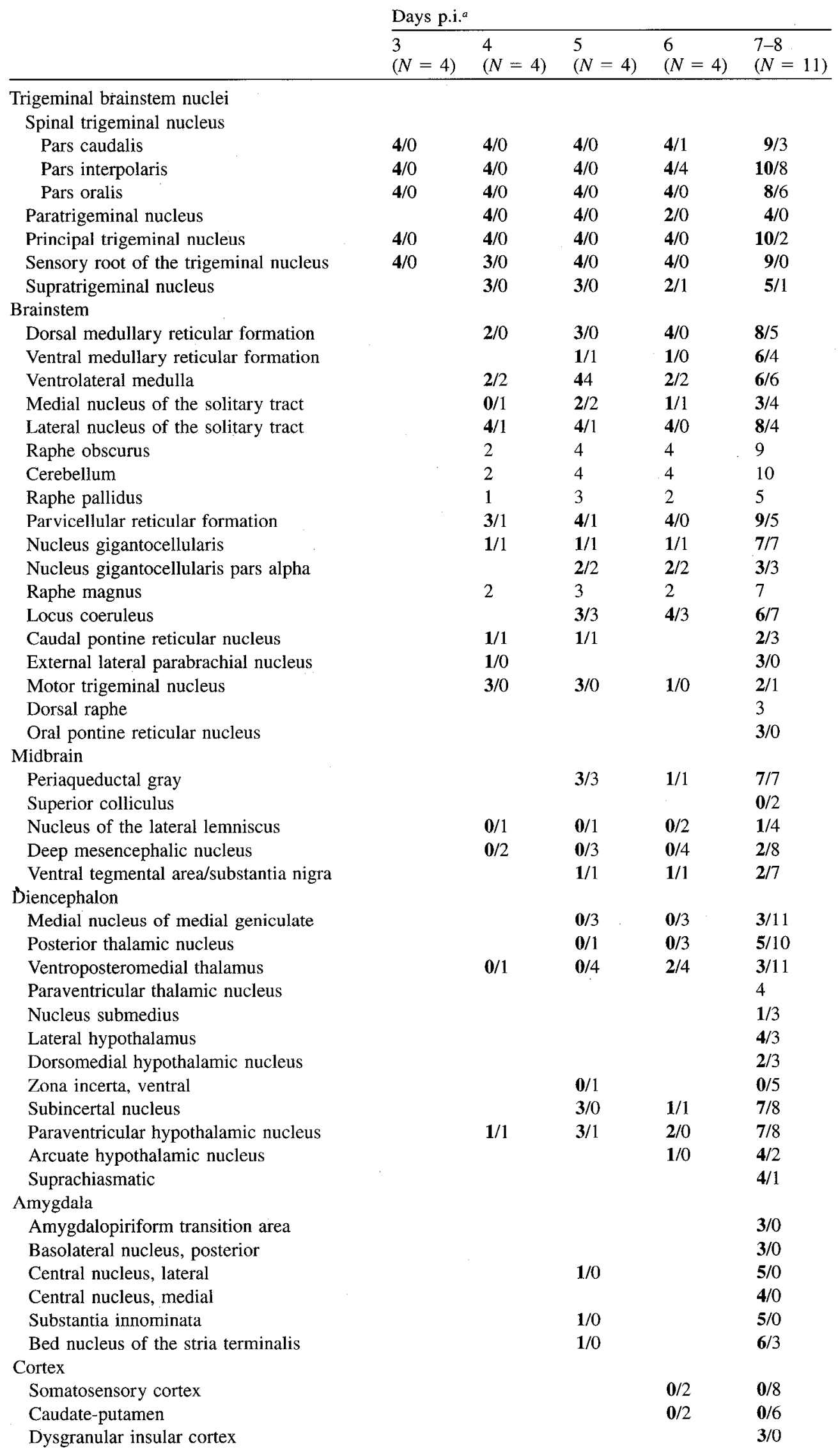

a Ipsilateral/contralateral to the tooth pulp inoculation; midline structures are presented as frequency only. 


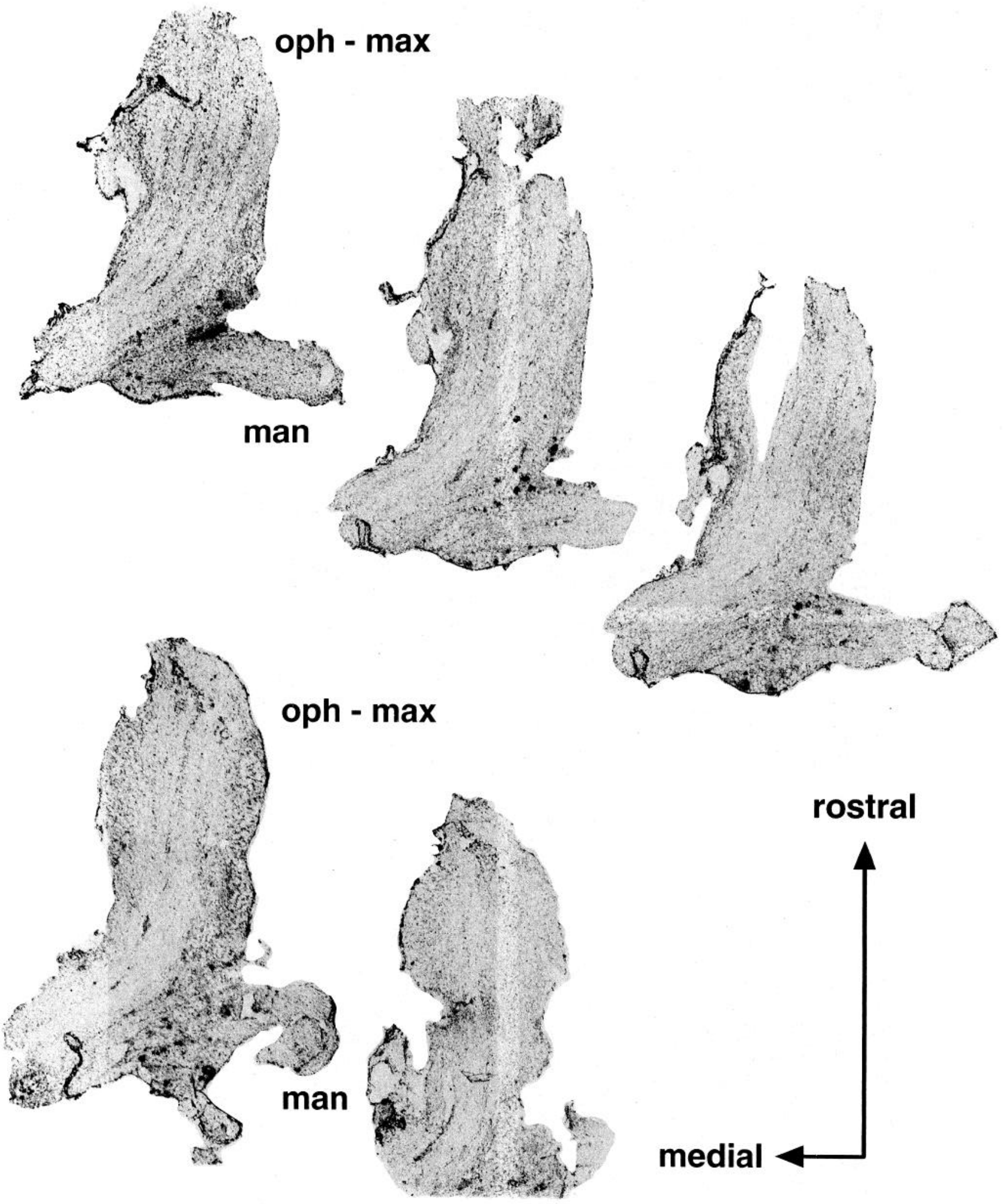

Figure 1. Typical distribution of viral labeling (black silver grains) in the ipsilateral semilunar (trigeminal) ganglion at day 3 p.i. as seen in serial, $25 \mu \mathrm{m}$ thick sections from a single animal. Note the restriction of viral labeling to the ganglion at the bifurcation of the mandibular (man) and ophthalmomaxillary (oph-max) divisions. Scale bar, $750 \mu \mathrm{m}$. 
2976 Barnett et al. - Anterograde Viral Tracing of Trigeminal Afferent Pathways
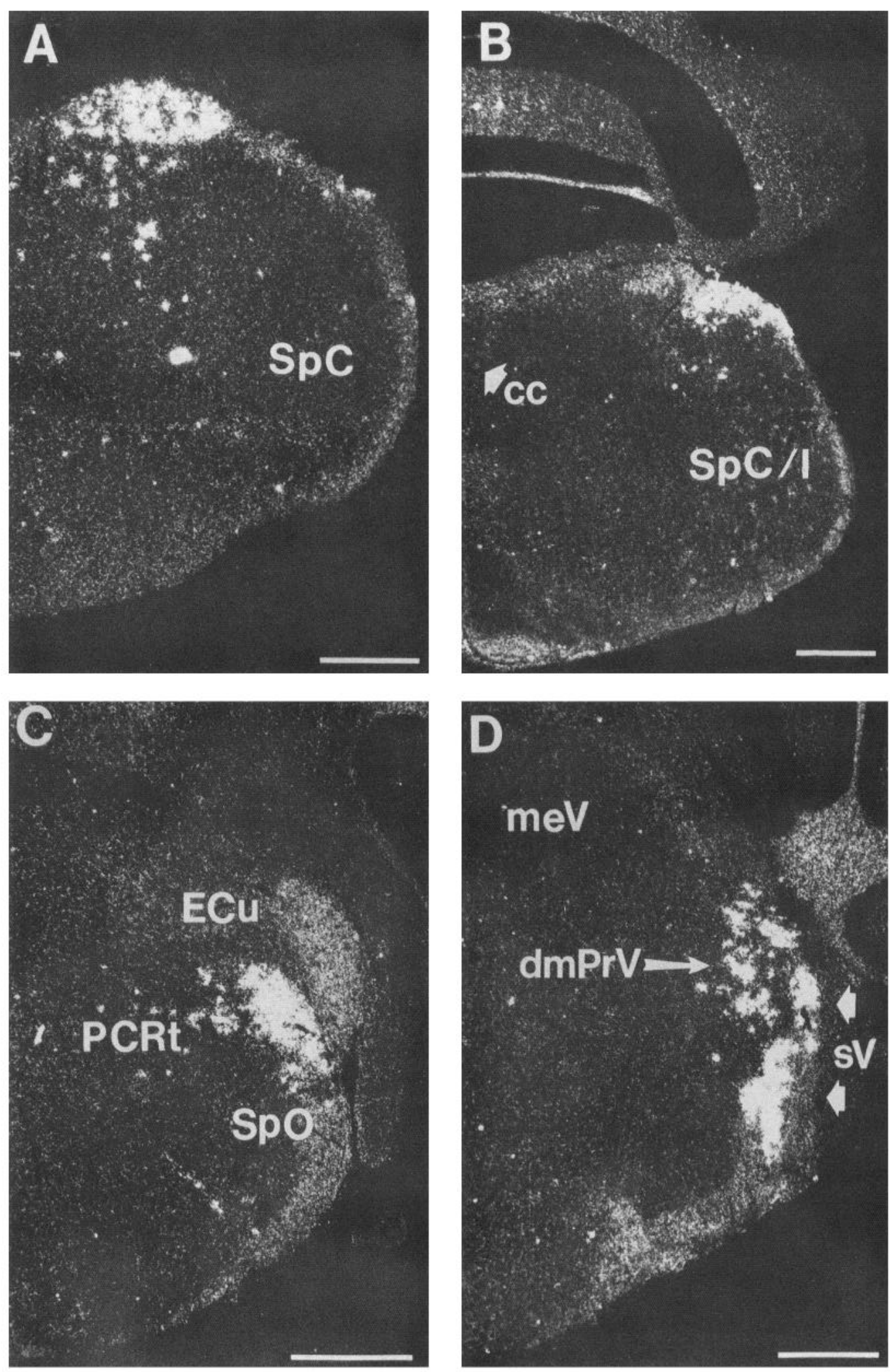

Figure 2. Initial infection of ipsilateral brainstem structures receiving dental input at day 3. Dark-field photomicrographs of coronal sections showing labeling (light areas) over, in $A$, dorsomedial region of the spinal trigeminal nucleus pars caudalis $(S p C)$ at approximately $1 \mathrm{~mm}$ caudal to the obex; $B$, dorsomedial spinal trigeminal nucleus at the pars caudalis/interpolaris junction $(S p C / I) ; C$, dorsomedial spinal trigeminal nucleus pars oralis $(\mathrm{SpO})$ with adjacent parvicellular reticular formation $(P C R t) ; D$, dorsomedial principal sensory nucleus $(\mathrm{dmPrV})$ and sensory root $(s V)$ of the trigeminal nerve. Note in $D$ the absence of labeling over the mesencephalic trigeminal nucleus $(m e V)$. The positions of the central canal ( $c c$ in $B)$ and the external cuneate nucleus $(E C u$ in $C)$ are also shown. Scale bars, $500 \mu \mathrm{m}$. 

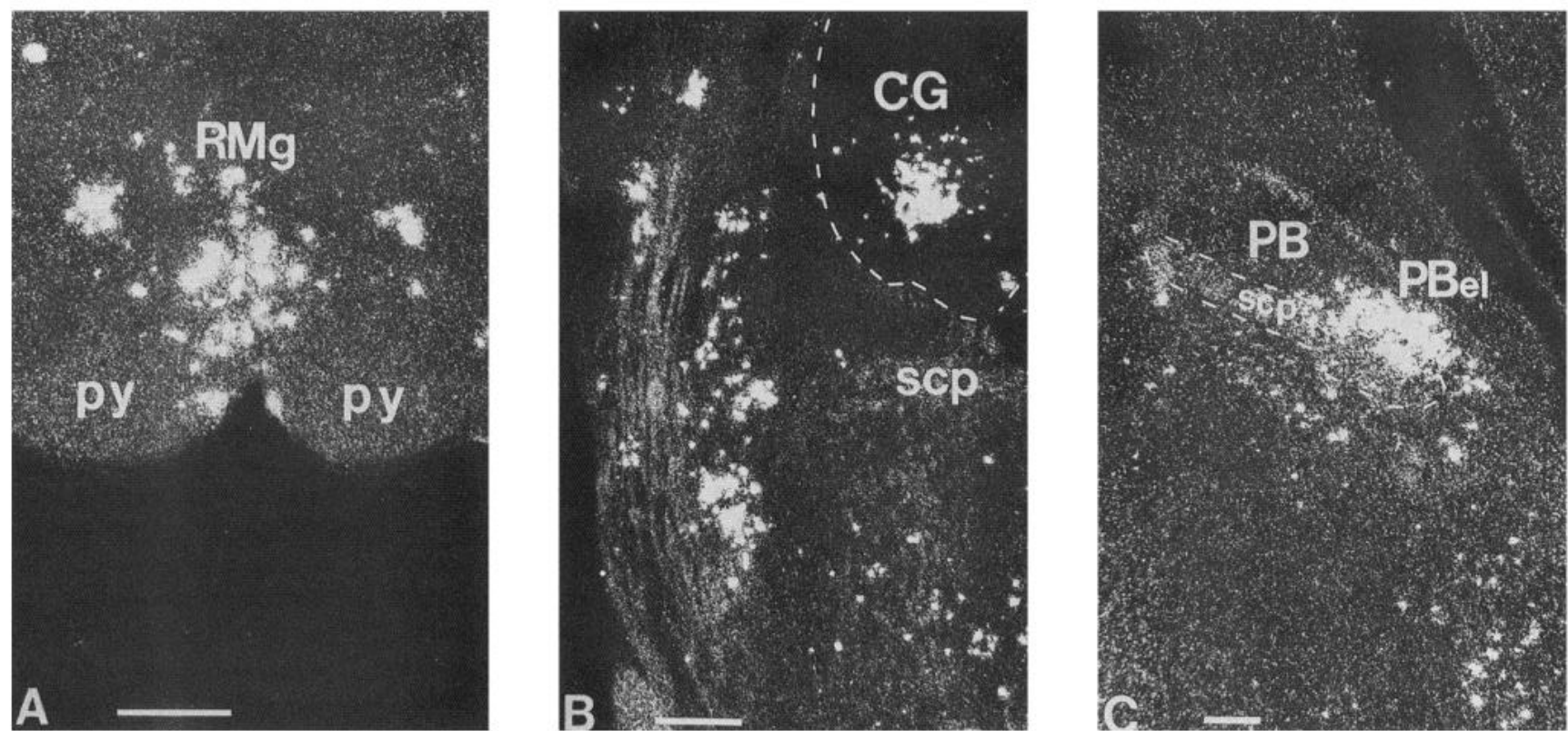

Figure 3. Dark-field photomicrograph of coronal sections showing structures infected in the pons and midbrain. A, Labeling in the raphe magnus $(R M g)$ at day $5 . B$, Infection in the contralateral central gray $(C G)$ and the lateral tegmentum was seen by day 5 . $C$, Labeling in the ipsilateral external lateral parabrachial nucleus $(\mathrm{PBel})$ was seen at days 7-8. PB, Parabrachial complex; $p y$, pyramidal tracts; scp, superior cerebellar peduncle. Scale bars, $250 \mu \mathrm{m}$.

(Fig. 1). No labeled cells were seen in the contralateral ganglia. Virus was also detected in the ipsilateral sensory root of the trigeminal nerve. In the brainstem, virus was detected ipsilaterally in structures previously shown to receive input from the tooth pulp. The majority of the labeling was detected in the dorsomedial extent of the partes caudalis (SpC) (Fig. $2 A$ ), interpolaris (SpI) (Fig. $2 B$ ), and oralis of the spinal trigeminal nucleus (Fig. $2 C$ ) and in the adjacent spinal trigeminal tract. There was no infection of the spinal trigeminal nucleus $(\mathrm{SpV})$ ventral to this dorsomedial region. Viral labeling in SpI extended medially into the dorsal parvicellular reticular formation (Fig. $2 \mathrm{C}$ ). The labeling extended rostrally into the dorsomedial division of the principal trigeminal sensory nucleus (PrV) (Fig. 2D). Virus was not found in the mesencephalic nucleus of the trigeminal nerve (Fig. $2 D$ ), the motor nucleus of the trigeminal nerve, the cervical spinal cord, or any contralateral brainstem structures.

Day 4. In addition to the previously mentioned structures, labeling was now seen in the paratrigeminal nucleus located dorsomedially in the spinal tract of the trigeminal nerve. Adjacent to the PrV, both the supratrigeminal nucleus and the motor nucleus of the trigeminal nerve now showed labeling. Virus was also detected in the inferior cerebellar peduncle, extending into the white matter of the cerebellum, but did not appear to be present in any of the deep cerebellar nuclei. There was additional evidence of spread to other secondary connections of tooth pulp afferents with occasional labeling in the three medullary raphe nuclei (obscurus, pallidus, and magnus) and additional parts of the medullary reticular formation.

Day 5. By day 5 there was additional evidence of spread along second order connections with infection of a number of brainstem and thalamic structures in addition to the labeling noted at day 4 . Infection of the three medullary raphe nuclei was now observed in almost every case (Fig. 3A). Further infection of the reticular formation was present with virus now commonly seen in the dorsal medullary reticular formation. Bilateral infection of the ventrolateral medulla and locus coeruleus was also detected. Labeled cells were seen ventral to the locus coeruleus in the region of both the subcoeruleus nucleus and the A5 noradrenergic cell group.

In the midbrain, labeling was detected in the contralateral lateral tegmentum in the area of the nuclei of the lateral lemniscus and in the ventrolateral central gray, most commonly bilaterally (Fig. $3 B$ ). In the caudal thalamus, virus was detected in the contralateral medial nucleus of the medial geniculate (MGm). Further rostrally, light labeling was seen in the medial and ventral parts of the contralateral ventroposteromedial thalamus (VPM). In the hypothalamus, labeling was seen in the parvicellular part of the ipsilateral paraventricular hypothalamic nucleus and dorsal hypothalamic area.

Day 6. At day 6 the pattern of labeling in the brainstem was similar to that seen at day 5 except that contralateral labeling was now seen in SpI and the adjacent dorsal parvicellular reticular formation. More robust labeling was now detected in the midbrain and thalamic structures infected at day 5 . In particular, labeling in the medial and ventral parts of VPM was clearly visible (Fig. $4 C$ ) and was also occasionally present in relatively small amounts ipsilaterally. Infection of the medial part of the contralateral posterior thalamic nucleus (PO) was now present in the majority of the mice (Fig. $4 B$ ).

The first appearance of virus in the cortex occurred at day 6 with two of the four mice showing labeling in lamina IV of the contralateral somatosensory cortex. In one case, the most ventral aspect of the secondary somatosensory cortex (SII), bordering on the granular insular cortex, was infected at the level of the anterior commissure. In the second case, the labeling was located more dorsally in the primary somatosensory cortex (SI), rostral to the anterior commissure. In both cases, adjacent areas of the caudate-putamen were infected, without evidence of viral spread across the intervening white matter of the external capsule. 

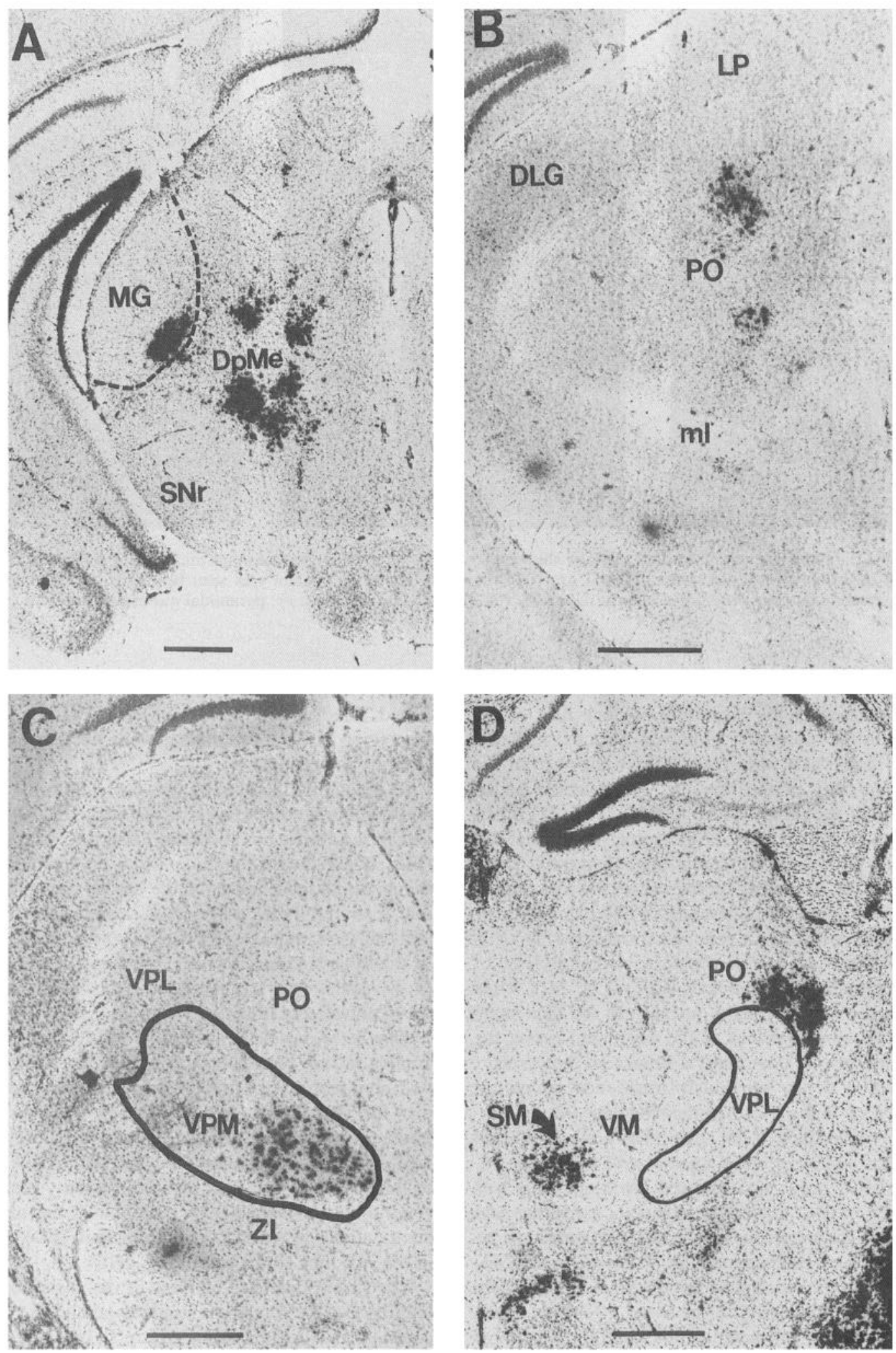

Figure 4. Viral spread to the thalamus. $A$, Infection of the contralateral medial nucleus of the medial geniculate and the deep mesencephalic nucleus $(D p M e)$ at day 7. $B$, Labeling in the contralateral posterior thalamic nucleus $(P O)$ at day 6 . $C$, Infection of the medial and ventral part of the contralateral ventroposteromedial thalamic nucleus $(V P M)$ at day $6 . D$, At days 7-8 virus was occasionally detected in rostral regions of the ipsilateral posterior thalamic nucleus and the nucleus submedius $(S M) . D L G$, Dorsal lateral geniculate nucleus; $L P$, lateral posterior thalamic nucleus; $M G$, medial geniculate complex; $m l$, medial lemniscus; $S N r$, substantia nigra pars reticularis; $V M$, ventromedial thalamic nucleus; $V P L$, ventroposterolateral thalamic nucleus; $Z I$, zona incerta. Scale bars, $500 \mu \mathrm{m}$. 

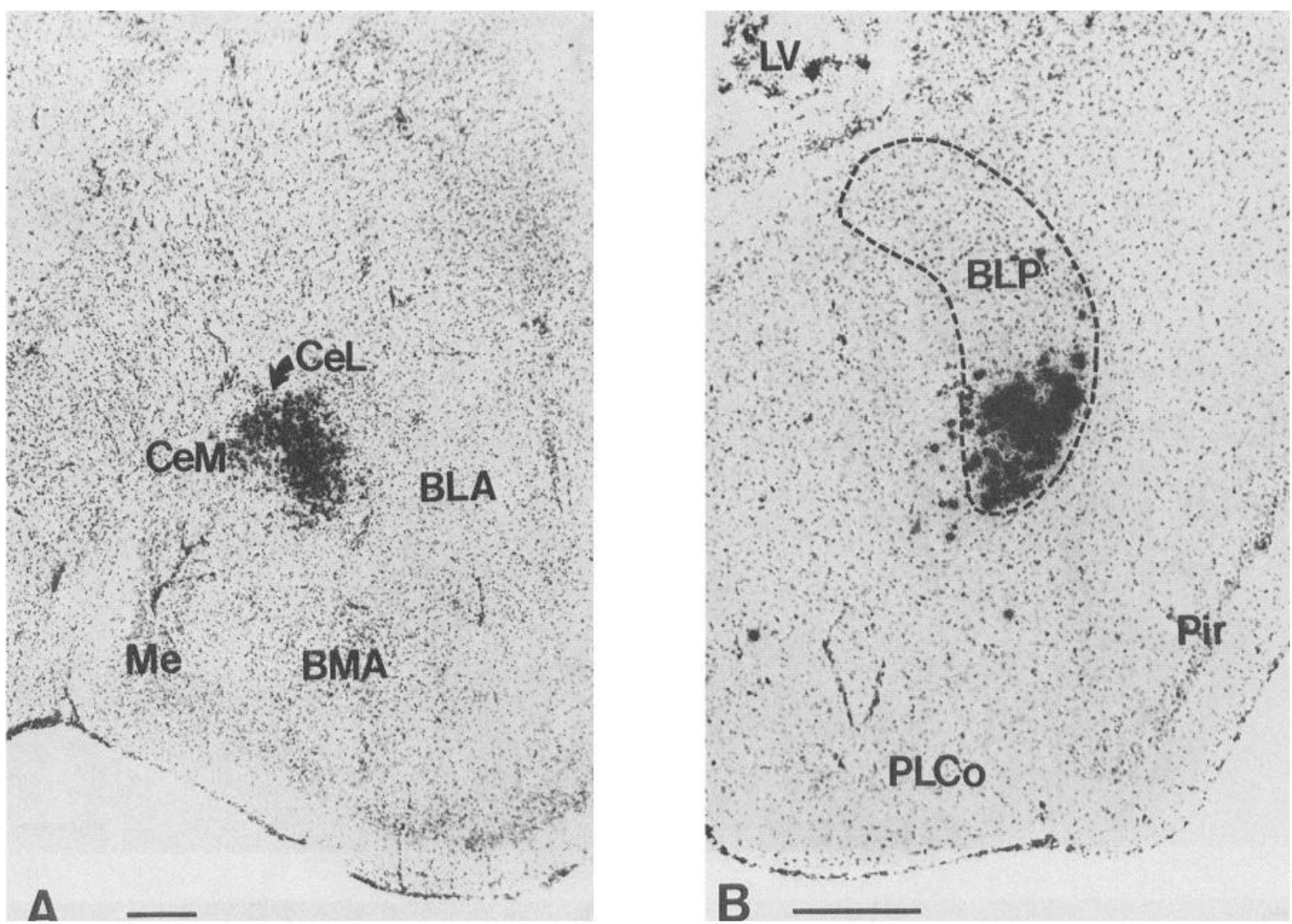

Figure 5. Labeling in the amygdala. $A$, Infection of the ipsilateral lateral division of the central amygdaloid nucleus $(\mathrm{CeL})$ at day $7 . B$, Labeling over part of the ipsilateral posterior basolateral amygdaloid nucleus $(B L P)$ at day $8 . B L A$, Anterior basolateral amygdaloid nucleus; $B M A$, anterior basomedial amygdaloid nucleus; $C e M$, medial division of the central amygdaloid nucleus; $L V$, lateral ventricle; $M e$, medial amygdaloid nucleus; Pir, piriform cortex; PLCo, posterior lateral amygdaloid nucleus. Scale bars, $250 \mu \mathrm{m}$.

Days 7 and 8 . The data from the mice sacrificed at day 7 and day $8(N=11)$ will be presented together since the extent of the infection was the same at both days. The progression of the infection in the brainstem consisted mainly of further involvement of the ipsilateral and contralateral reticular formation, including the ventral medullary reticular formation, nucleus gigantocellularis, and the caudal pontine reticular formation. Infection of the dorsomedial region of the contralateral spinal trigeminal nucleus was now seen in every case.

In the midbrain three of the mice had prominent labeling in the ipsilateral external lateral nucleus of the parabrachial complex (PBel) (Fig. 3C). Labeling was occasionally seen in the dorsal raphe nucleus and the oral pontine reticular nucleus. In the thalamus, infection of the contralateral MGm, PO, and VPM was universal, with ipsilateral labeling seen in these nuclei in approximately one-third of the mice. Labeling was also seen adjacent to the MGm in the deep mesencephalic nucleus (Fig. $4 A$ ). More rostrally in the thalamus, virus was detected in the paraventricular thalamic nucleus in four mice and the contralateral nucleus submedius in three mice. In one case, nucleus submedius labeling was seen ipsilaterally (Fig. 4D). Ipsilateral infection of the rostral PO was also seen in four of the mice. Unlike the ipsilateral infection of the MGm and VPM which was located in the same regions as that seen contralaterally, the ipsilateral infection of the PO was located only in the more rostral extent of this nucleus (Fig. $4 D$ ). Infection of the ventral tegmental area/substantia nigra (A10) was seen in the majority of cases, predominantly contralateral. The three mice which had labeling in the PBel all showed labeling in the amygdaloid-piriform transition area and posterior basolateral amygdaloid nucleus (Fig. 5B). Labeling was also seen in the central amygdaloid nucleus $(\mathrm{Ce})$ in half of the mice, which in all but one case (Fig. 5A) was present in both the medial and lateral subnuclei. Labeling in the contralateral ventral zona incerta was also seen in half of the mice.

Infection of the hypothalamus was seen in every case, with the bulk of the labeling observed bilaterally in the paraventricular hypothalamus. Virus was detected in the lateral hypothalamus and the dorsomedial, suprachiasmatic, and arcuate nuclei of the hypothalamus in four mice. Labeling was also seen in the sublenticular substantia innominata in five mice and the bed nucleus of the stria terminalis in seven mice. This labeling was primarily ipsilateral and was for the most part restricted to the lateral and ventral divisions of the bed nucleus.

Only one mouse showed no evidence of cortical infection. The remainder showed labeling in either the contralateral somatosensory cortex ( 9 of 11) and/or the ipsilateral dysgranular insular cortex (3 of 11). Labeling in SII commonly started just caudal to the anterior commissure and was found ventrally in the lower jaw region (Fig. $6 A, B$ ). The infection of SI typically occurred rostral to the anterior commissure, also in the lower jaw region (Fig. $6 \mathrm{C}$ ), although in mice with more advanced infections, labeling extended to the caudal end of SI, and became more medial (Fig. 6B). Most commonly the infection began in 

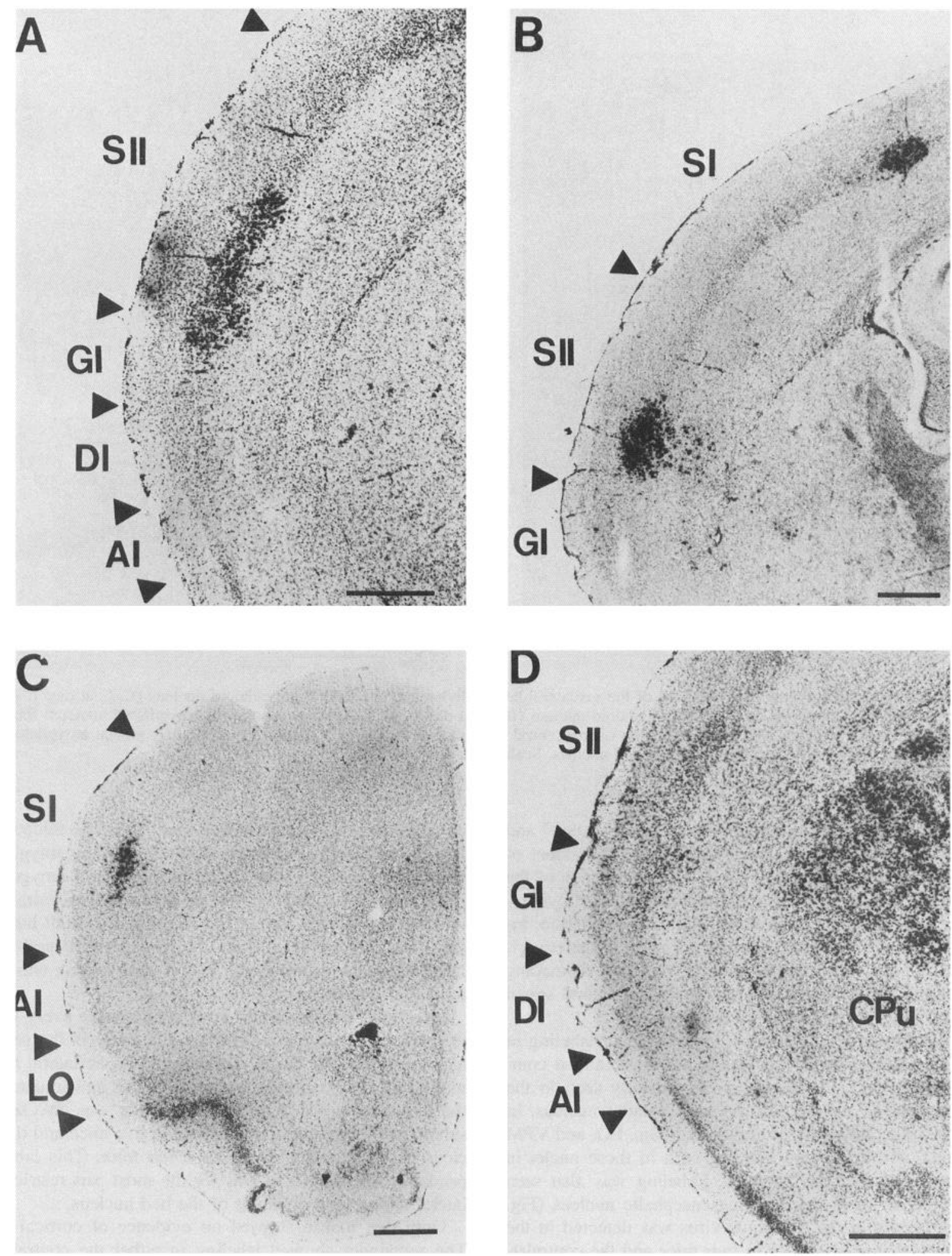

Figure 6. Infection of contralateral somatosensory cortex at days 7-8. A, Infection of the secondary somatosensory cortex (SII) first appeared in lamina IV. $B$, Infection in restricted regions of both the primary $(S I)$ and secondary somatosensory cortices. $C$, Infection of the rostral lower jaw region of SI. $D$, As areas of somatosensory cortex were infected, nearby regions of caudate-putamen $(C P u)$ matrix were also labeled. $A I$, Agranular insular cortex; DI, dysgranular insular cortex; GI, granular insular cortex; $L O$, lateral orbital cortex. Scale bars, $500 \mu \mathrm{m}$. 

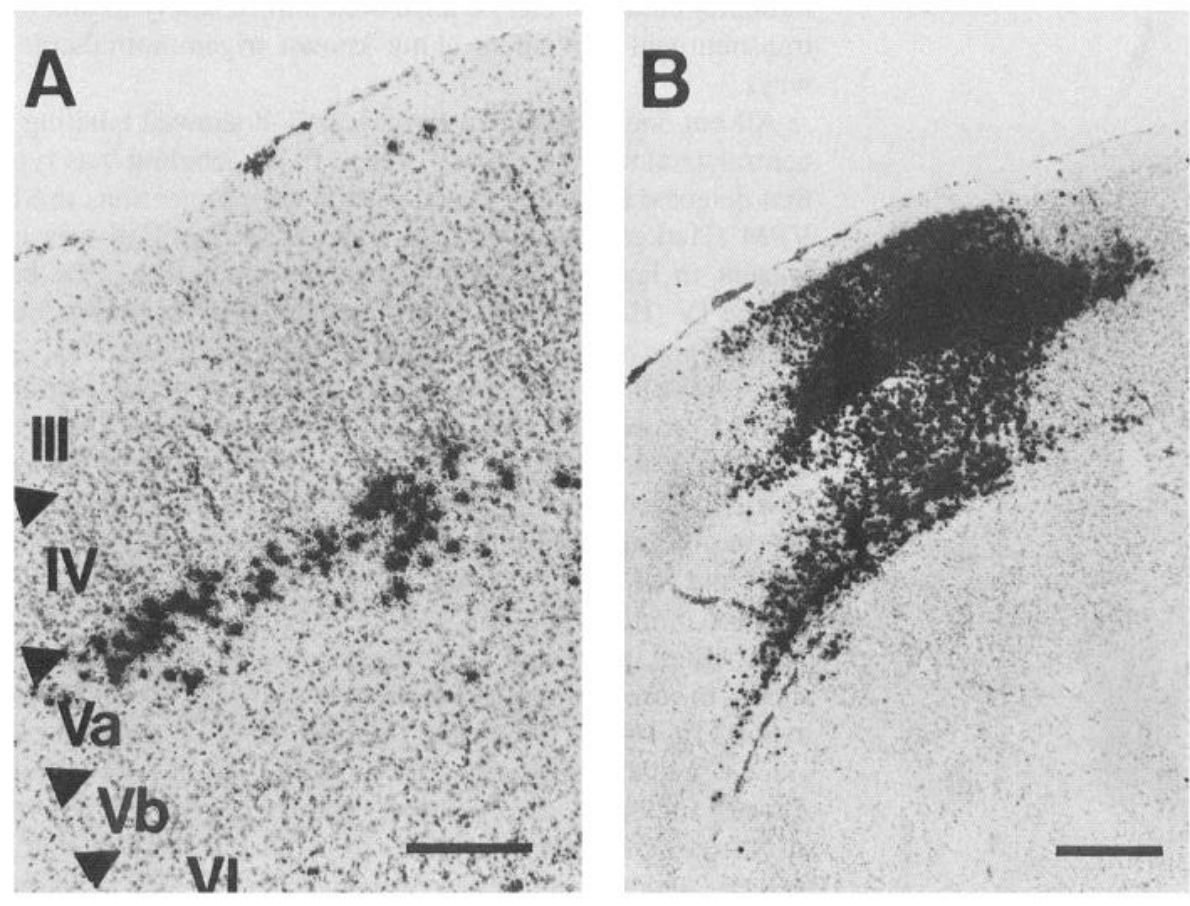

Figure 7. Infection of laminae $\mathrm{V}$ and VI of contralateral SI. A, Labeling was initially seen in lamina Va of SI in three mice at days 7-8. B, Labeling over lamina Va was often more extensive than that seen in lamina IV. Viral spread to lamina VI was also apparent in heavily infected cases, and did not appear to be caused by local spread of virus from nearby laminae. Scale bars: $A, 250 \mu \mathrm{m} ; B, 500 \mu \mathrm{m}$.

lamina IV, but in three cases labeling in the SI was first detected in lamina Va (Fig. 7A). When both laminae IV and Va of SI were infected, labeling in Va often extended laterally outside the boundaries of the lamina IV labeling (Fig. 7B). Several cases also showed labeling in lamina VI, which was not contiguous with labeling in lamina $\mathrm{V}$ and often extended beyond the boundaries of lamina IV labeling (Fig. 7B). Finally, in heavily infected cases, laminae II, III, and Vb were also infected (Fig. 7B). The greater the extent of the infection of somatosensory cortex, the more common and more robust was labeling in nearby regions of the caudate-putamen (Fig. 6D). Infection of the ipsilateral dysgranular cortex was consistently associated with infection of the ipsilateral PBel, amygdala, and rostral PO. The infection of this cortical area was first seen in laminae II and III (Fig. 8), with occasional spread to layer V.

\section{Discussion}

\section{Anterograde transneuronal spread of virus}

Although most previous reports showed that HSV-1 spread transneuronally in a retrograde direction (McLean et al., 1989; Blessing et al., 1991; Barnett et al., 1993b), it was recently reported that strain $\mathrm{H} 129$ spread in an anterograde fashion and our data are in agreement with these initial observations (Zemanick et al., 1991). Anterograde transneuronal spread was clearly evident, for example, in the initial infection of lamina IV of somatosensory cortex, as would be expected from anterograde spread of virus along thalamocortical projections. The results also differ significantly from those obtained when a retrograde spreading strain, HSV-1 strain 17 , was inoculated into the tooth pulp (Barnett et al., 1994).

\section{Specificity of viral spread along pulpal afferent pathways}

The finding of a very restricted distribution of infected cells in the semilunar ganglion (Fig. 1), as well as the restriction of infection to the dorsomedial part of the spinal trigeminal nucleus, even at the latest time points sampled (day 8 p.i.), is consis- tent with the known organization of the first-order connections of the mandibular incisor tooth pulp (Gregg and Dixon, 1973; Shigenaga et al., 1976; Shelhammer et al., 1984; Takemura et al., 1991). This finding also suggests that if intraganglionic spread of virus occurred, it did not include nondental afferents. Further, the restricted infection of jaw regions of VPM (Fig. $4 C$ ) and of SI and SII (Fig. 6A-C) suggests that, at a minimum, subsequent transneuronal viral movement was restricted to second- and third-order jaw afferent pathways. A key question, however, is the degree to which the pattern of infection reflects viral movement along pulpal nociceptive pathways. Dental pulp nerves consist primarily of small diameter, unmyelinated axons, but include a small number of large diameter fibers as well as unmyelinated and thinly myelinated postganglionic sympathetic fibers (Fried et al., 1988). Electrophysiological and anatomical studies suggest that some pulpal afferents have characteristics of mechanoreceptors, raising the issue of whether pulpal afferents are entirely nociceptive (Dong et al., 1985; Fried et al., 1989). Clearly, at present we have no evidence that HSV-1 selectively infects one type of pulpal afferent over another, and the most cautious interpretation of the present findings is that both nociceptive and non-nociceptive pulpal afferents were infected. Nonetheless, with the exception of a few structures, such as the dysgranular insular cortex, all of the medullary, mesencephalic, thalamic, and forebrain structures found to be infected have been shown electrophysiologically to contain neurons responsive to nociceptive stimulation of the tooth pulp. Thus, the observed pattern of infection reported here can be attributed to transneuronal movement of virus along dental nociceptive pathways.

\section{Spread of HSV-1 along two separate pathways}

Comparing the temporal sequence of infected structures with the known anatomy of ascending trigeminal pathways suggests that after virus enters the brainstem it follows two distinct projection systems to reach the cortex (Fig. 9). While this division is clearly an oversimplification, it may, in part, reflect the physiologically 


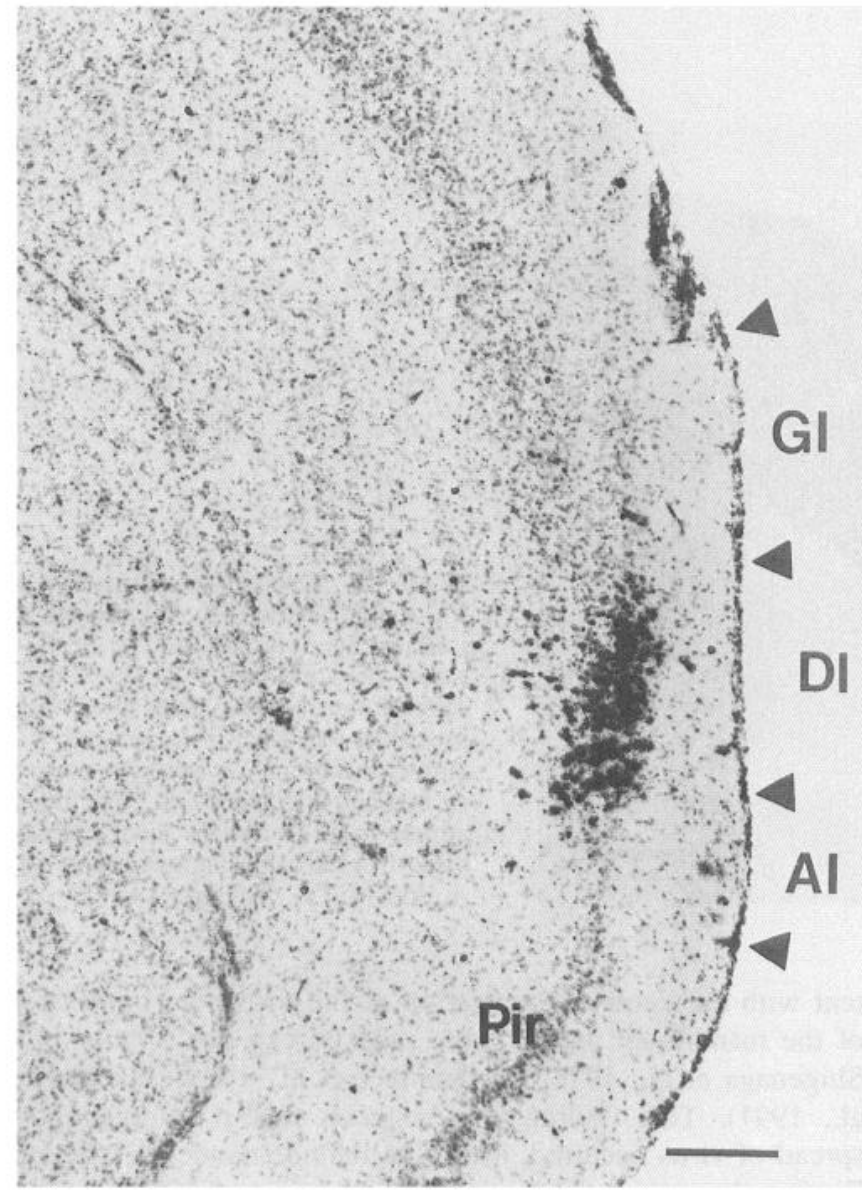

Figure 8. Infection of laminae II/III of the ipsilateral dysgranular insular cortex $(D I)$ was seen in three cases at days $7-8$ and was always associated with labeling in the ipsilateral external lateral parabrachial, posterior basolateral amygdaloid, and posterior thalamic nuclei. $A I$, Agranular insular cortex; GI, granular insular cortex; Pir, piriform cortex. Scale bars, $250 \mu \mathrm{m}$.

based division of nociception into sensory-discriminative and affective-motivational components (Albe-Fessard, 1985; Snow et al., 1992).

The contralateral trigeminothalamocortical pathway. Shortly after infection of the sensory trigeminal nuclei, labeling was consistently present in contralateral MGm, PO, and in the ventral and medial parts of VPM. Projections from PrV and SpI to the contralateral MGm, VPM, PO (Peschanski, 1984; Roger and Cadusseau, 1984) and from the $\mathrm{SpC}$ to the nucleus submedius bilaterally (Yoshida et al., 1991) have been described anatomically and physiologically. Incisor tooth pulp stimulation in the rat has been shown to activate neurons in the MGm, PO, and the ventral part of ventrobasal thalamic complex (Shigenaga et al., 1973). Neurons in the SpC which project to the ventromedial VPM and PO are located in dorsomedial part of lamina 1 where neurons responsive to lower incisor tooth pulp stimulation are also located (Shigenaga et al., 1979). Further, the restricted pattern of labeling in VPM is consistent with the somatotopic organization of the projections from PrV, SpI, and SpC to VPM (Erzurumlu and Killackey, 1980; Peschanski, 1984). The more widespread infection of PO is consistent with the diffusely organized trigeminal input to PO (Peschanski, 1984; Chiaia et al., 1991). Thus, the observed pattern of viral infection in the con- tralateral thalamus can be attributed almost solely to anterograde transneuronal movement along known trigeminothalamic pathways.

All but one of the mice from days $7-8$ showed labeling in the contralateral somatosensory cortex. In SI, labeling was typically first detected in lamina IV, consistent with projections to SI from VPM (Herkenham, 1980). In three cases labeling was clearly present in lamina $\mathrm{Va}$, which receives input from PO, but not lamina IV (Herkenham, 1980). In more heavily infected brains, labeling was also seen in lamina VI of SI (Fig. $8 B$ ), which likely represents either intralaminar spread of virus or viral spread via a VPM projection to this lamina (Herkenham, 1980). Labeling in SII was first seen in lamina IV, consistent with projections from PO (Herkenham, 1980). Labeling in other laminae is likely due to ipsilateral corticocortical spread between the face areas of SI and SII or intracortical spread (Carvell and Simons, 1987; Koralek et al., 1990).

Labeling in SI and SII was located in regions previously shown to receive input from the lower jaw (Welker, 1971; Chapin and Lin, 1984; Carvell and Simons, 1986). A study of cerebral glucose metabolism evoked by maxillary tooth pulp stimulation showed increased deoxyglucose uptake in overlapping regions of SI and SII similar to those infected by virus in this study (Shetter and Sweet, 1979). Shigenaga et al. (1974) found that electrical stimulation of the two mandibular incisors also mapped to similar regions in SI and SII, which, unlike ours, did not overlap. Overall, the initial pattern of infection in SI and SII can be attributed to virus moving along somatotopically organized projections from the sensory trigeminal nuclei to thalamus, as well as from VPM and PO to SI and PO to SII.

The ipsilateral pathways. Projections from the dorsal $\mathrm{SpV}$ to the PBel have been well characterized (Cechetto et al., 1985) and may be part of a trigeminopontoamygdaloid pathway for pain (Bernard et al., 1989). The appearance of labeling in this structure did not typically occur, however, until day 7 , suggesting that it may have been infected via another structure. Hayashi (1992) has suggested, based on electrophysiological evidence in the cat, that the bulbar reticular formation may relay nociception information to the parabrachial complex (PB).

Labeling in the amygdala and its basal forebrain extensions typically appeared on day 7 , with half of the animals at this time having labeling in $\mathrm{Ce}$, and several other animals showing infection of the posterior basolateral amygdaloid nucleus. Nociceptive responses have been recorded from Ce (Bernard et al., 1990, 1992) and in cats, the reflexive opening of the jaw in response to tooth pulp stimulation is inhibited by direct and indirect $\mathrm{Ce}$ stimulation (Kowada et al., 1992). Our data suggest that additional basal forebrain regions, such as the bed nucleus of the stria terminalis and the sublenticular substantia innominata, may also receive sensory input from the tooth pulp. Nociceptive information is believed to be relayed to the amygdala from the trigeminal sensory nuclei and spinal cord via the lateral PB (e.g., Bernard et al., 1989). This is in line with our finding that the labeling in the posterior basolateral amygdaloid nucleus appeared at the same (relatively late) time as did PBel labeling. The restricted pattern of PB labeling, that is, in the PBel, corresponds to the location of parabrachioamygdaloid neurons activated by noxious stimulation of the face and tongue (Bernard et al., 1990).

Infection of the ipsilateral dysgranular insular cortex was not seen in every case, but when present, was associated with infection of the ipsilateral PBel, rostral PO, and posterior basolat- 


\section{CONTRALATERAL}

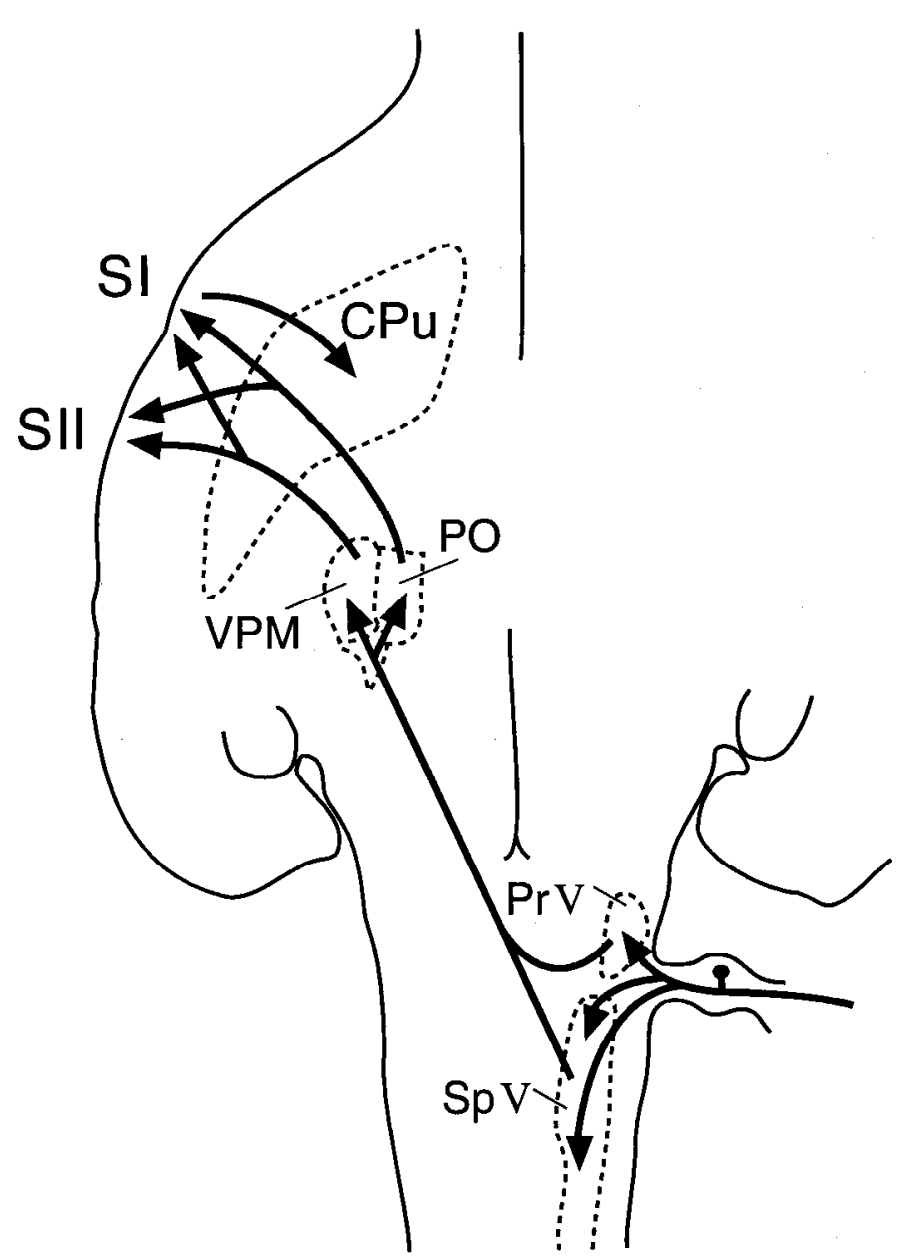

IPSILATERAL

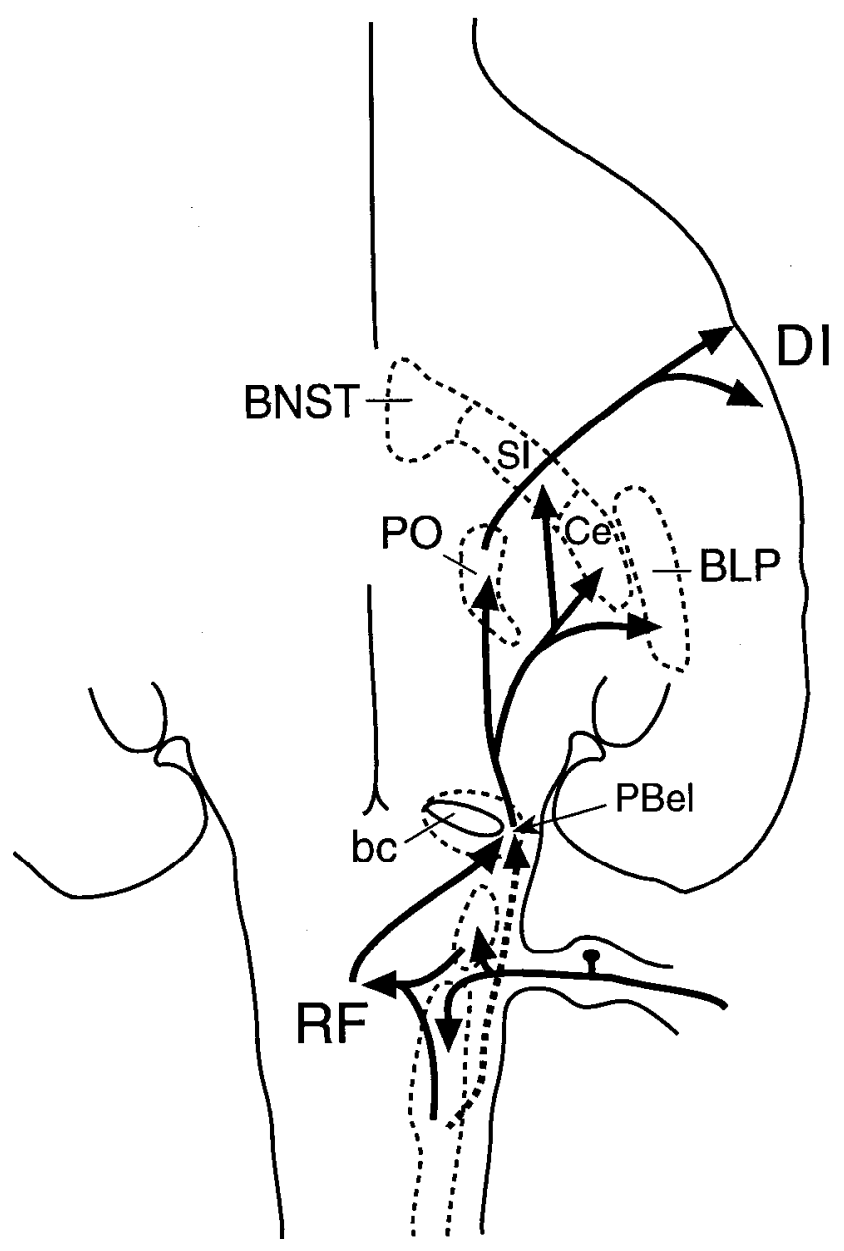

Figure 9. A schematic diagram of the probable routes of transneuronal viral spread from the tooth pulp to the contralateral somatosensory cortex and ipsilateral dysgranular insular cortex. Bilaterally infected structures in the brainstem, midbrain, and diencephalon are not shown. The dotted line denotes an alternative pathway from $\mathrm{SpV}$ to the PBel. $b c$, brachium conjunctivum; $B L P$, posterior basolateral amygdaloid nucleus; $B N S T$, bed nucleus of the stria terminalis; $S I$, substantia innominata; $R F$, reticular formation; other abbreviations as in text and previous figures.

eral amygdaloid nucleus. The PBel projects to the rostral PO (Roger and Cadusseau, 1984) and both the PB and the rostral PO project to the dysgranular insular cortex (Yasui et al., 1990). The dysgranular insular cortex has been designated the primary gustatory cortex (Cechetto and Saper, 1987). The absence of viral labeling in the parvicellular part of VPM, however, suggests that infection of gustatory pathways cannot account for the infection of the dysgranular insular cortex The present results thus suggest that in addition to a gustatory input, the dysgranular insular cortex receives potential nociceptive input originating in the tooth pulp.

Maxillary tooth pulp stimulation causes an increase in 2-deoxyglucose uptake in the ipsilateral dysgranular insular cortex (Shetter and Sweet, 1979) and studies in humans have shown bilateral increases in cerebral blood flow in the dysgranular insular cortex after peripheral nociceptive stimulation (Coghill et al., 1994). Stimulation of the dysgranular/agranular insular cortex induces complex rhythmical jaw movements (Zhang and Sasamoto, 1990). Taken with the present evidence for a dental afferent input to the dysgranular insular cortex, and the evidence for a gustatory input as well (Cechetto and Saper, 1987), these findings suggest that the dysgranular insular cortex may modulate jaw movement reflexes in response to noxious, mcchanical, or gustatory oral stimuli.

\section{References}

Albe-Fessard D, Berkley KJ, Kruger L, Ralston HJ III, Willis WD (1985) Diencephalic mechanisms of pain sensation. Brain Res Rev 9:217-296

Atkinson ME, Kenyon C (1990) Collateral branching innervation of rat molar teeth from trigeminal ganglion cells shown by double labelling with fluorescent retrograde tracers. Brain Res 508:289-292.

Barnett EM, Cassell MD, Perlman S (1993a) Two neurotropic viruses, herpes simplex virus type 1 and mouse hepatitis virus, spread along different neural pathways from the main olfactory bulb. Neuroscience 57:1007-1025.

Barnett EM, Evans GD, Cassell MD, Perlman S (1993b) Anterograde transneuronal spread of herpes simplex virus from the murine tooth pulp to two cortical areas associated with jaw movement. Soc Neurosci Abstr 19:1210.

Barnett EM, Jacobsen G, Evans GD, Cassell MD, Perlman S (1994) Herpes simplex encephalitis of the temporal cortex and limbic system after trigeminal nerve inoculation. J Infect Dis 169:782-786. 
Bernard JF, Besson JM (1990) The spino(trigemino)pontoamygdaloid pathways: electrophysiological evidence for an involvement in pain processes. J Neurophysiol 68:473-390.

Bernard JГ; Peschanski M, Besson JM (1989) A possible spino (trigemino)-ponto-amygdaloid pathway for pain. Neurosci Lett 100:8388

Bernard JF, Carroue J, Besson JM (1991) Efferent projections from the external parabrachial area to the forebrain: a Phaseolus vulgaris leucoagglutinin study in the rat. Neurosci Lett 122:257-260.

Bernard JF, Huang GF, Besson JM (1992) The nucleus centralis of the amygdala and the globus pallidus ventralis: electrophysiological evidence for an involvement in pain processes. J Neurophysiol 68:551569.

Blessing WW, Li Y-W, Wesselingh SL (1991) Transneuronal transport of herpes simplex virus from the cervical vagus to brain neurons with axonal inputs to central vagal sensory nuclei in the rat. Neuroscience $42: 261-274$.

Carvell GE, Simons DJ (1986) Somatotopic organization of the second somatosensory area (SII) in the cerebral cortex of the mouse. Somatosens Res 3:213-237.

Carvell GE, Simons DJ (1987) Thalamic and corticocortical connection of the second somatosensory area of the mouse. J Comp Neurol 265: $409-427$.

Cechetto DF, Saper CB (1987) Evidence for a viscerotopic sensory representation in the cortex and thalamus in the rat. $\mathbf{J}$ Comp Neurol $262: 27-45$.

Cechetto DF, Standaert DG, Saper CB (1985) Spinal and trigeminal dorsal horn projections to the parabrachial nucleus in the rat. J Comp Neurol 240:153-160.

Chapin JK, Lin C-S (1984) Mapping the body representation in the SI cortex of anesthetized and awake rats. J Comp Neurol 229:199-213.

Chiaia NL, Rhoades RW, Bennett-Clarke CA, Fish SE, Killackey HP (1991) Thalamic processing of vibrissal information in the rat. I. Afferent input to the medial ventral posterior and posterior nuclei. J Comp Neurol 314:201-216.

Coghill RC, Talbot JD, Evans AC, Meyer E, Gjedde A, Bushnell MC, Duncan GH (1994) Distributed processing of pain and vibration by the human brain. J Neurosci 14:4095-4108.

Dong WK, Chudler EH, Martin RF (1985) Physiological properties of intradental mechanoreceptors. Brain Res 334:389-395.

Erzurumlu RS, Killackey HP (1980) Diencephalic projections of the subnucleus interpolaris of the brainstem trigeminal complex in the rat. Neuroscience 5:1891-1901.

Fried K, Aldskogius H, Hildebrand C (1988) Proportion of unmyelinated axons in rat molar and incisor tooth pulps following neonatal capsaicin treatment and/or sympathectomy. Brain Res 463:118-123.

Fried K, Arvidsson J, Robertson B, Brodin E, Theodorsson E (1989) Combined retrograde tracing and enzyme/immunohistochemistry of trigeminal ganglion cell bodies innervating tooth pulps in the rat. Neuroscience 33:101-109.

Gonzalo-Sanz LM, Insausti R (1980) Fibers of trigeminal mesencephalic neurons in the maxillary nerve of the rat. Neurosci Lett 16: 137-141.

Gregg JM, Dixon AD (1973) Somatotopic organization of the trigeminal ganglion in the rat. Arch Oral Biol 18:487-498.

Hayashi H (1992) Somatosensory pathways from the trigeminal nucleus to the mesencephalic parabrachial area. In: Processing and inhibition of nociceptive information (Inoki R, Shigenaga Y, Tohyama M, eds), pp 109-114. Amsterdam: Elsevier.

Herkenham M (1980) Laminar organization of thalamic projections to the rat neocortex. Science 207:532-535.

Johnson RT (1964) The pathogenesis of herpes virus encephalitis. I. Virus pathways to the nervous system of suckling mice demonstrated by fluorescent antibody staining. I Fxp Med 199:343-355.

Koralek K-A, Olavarria J, Killackey HP (1990) Areal and laminar or- ganization of corticocortical projections in the rat somatosensory cortex. J Comp Neurol 299:133-150.

Kowada K, Kawarada K, Matsumoto N, Suzuki TA (1992) Inhibitory effect of the central amygdaloid nucleus on the jaw-opening reflex induced by tooth pulp stimulation in the cat. In: Processing and inhibition of nociceptive information (Inoki R, Shigenaga Y, Tohyama M, eds), pp 219-222. Amsterdan: Elsevier.

Marfurt CF, Turner DF (1984) The central projections of tooth pulp afferent neurons in the rat as determined by the transganglionic transport of horseradish peroxidase. J Comp Neurol 223:535-547.

McLean JH, Shipley MT, Bernstein DI (1989) Golgi-like, transneuronal retrograde labelling with CNS injection of herpes simplex virus type 1. Brain Res Bull 22:867-881.

Perlman S, Jacobsen G, Moore S (1988) Regional localization of virus in the central nervous system of persistently infected with murine coronavirus JHM. Virology 166:328-338.

Peschanski M (1984) Trigeminal afferents to the diencephalon in the rat. Neuroscience 12:465-487.

Roger M, Cadusseau J (1984) Afferent connections of the nucleus posterior thalami in the rat, with some evolutionary and functional considerations. J Hirnforsch 25:473-485.

Roland P (1992) Cortical representation of pain. Trends Neurosci 15: 3-5.

Sessle BJ (1987) The neurobiology of facial and dental pain: present knowledge, future directions. J Dent Res 66:962-981,

Shellhammer SB, Gowgiel JM, Gaik GC, Weine FS (1984) Somatotopic organization and transmedian pathways of the rat trigeminal ganglion. J Dent Res 63:1289-1292.

Shetter AG, Sweet WH (1979) Relative cerebral glucose metabolism evoked by dental-pulp stimulation in the rat. J Neurosurg 51:12-17.

Shigenaga Y, Matano S, Okada K, Sakai A (1973) The effects of tooth pulp stimulation in the thalamus and hypothalamus of the rat. Brain Res 63:402-407.

Shigenaga Y, Matano S, Kusuyama M, Sakai A (1974) Cortical neurons responding to electrical stimulation of the rat's incisor pulp. Brain Res 7:153-156.

Shigenaga Y, Sakai A, Okada K (1976) Effects of tooth pulp stimulation in trigeminal nucleus caudalis and adjacent reticular formation in rat. Brain Res 103:400-406.

Shigenaga Y, Takabatake M, Sugimoto T, Sakai A (1979) Neurons in marginal layer of trigeminal nucleus caudalis projecting to ventrobasal complex (VB) and posterior nuclear group (PO) demonstrated by retrograde labeling with horseradish peroxidase. Brain Res 166: 391-396.

Shipley MT, Geinisman Y (1984) Anatomical evidence for convergence of olfactory, gustatory, and visceral afferent pathways in mouse cerebral cortex. Brain Res Bull 12:221-226.

Snow PJ, Lumb BM, Cervero F (1992) The representation of prolonged and intense, noxious somatic and visceral stimuli in the ventrolateral orbital cortex of the cat. Pain 48:89-99.

Takemura M, Sugimoto T, Shigenaga Y (1991) Difference in central projection of primary afferent innervating facial and intraoral structures in the rat. Exp Neurol 111:324-331.

Welker C (1971) Microelectrode delineation of fine grain somatotopic organization of SMI cerebral neocortex in albino rat. Brain Res 26: 259-275.

Yasui Y, Breder CD, Saper CB, Cechetto DF (1991). Autonomic responses and efferent pathways from the insular cortex in the rat. $\mathrm{J}$ Comp Neurol 303:355-374.

Yoshida A, Dostrovsky JO, Sessle BJ, Chiang CY (1991) Trigeminal projections to the nucleus submedius of the thalamus in the rat. $J$ Comp Neurol 307:609-625.

Zemanick MC, Strick PL, Dix RD (1991) Direction of transneuronal transport of herpes simplex virus 1 in the primate motor system is strain-dependent. Proc Natl Acad Sci USA 88:8048-8051.

Zhang G, Sasamoto K (1990) Projections of two separate cortical areas for rhythmical jaw movements in the rat. Brain Res Bull 24:221230. 